\title{
Numerical Analysis of Subsoil-Reinforced Concrete Slab Interaction
}

\author{
Tuan Duc LE ${ }^{1}$, Qui Thanh NGUYEN ${ }^{1}$ and Radim CAJKA ${ }^{2}$ \\ ${ }^{1}$ Department of Structural Mechanics, Faculty of Civil Engineering, VSB - Technical University of Ostrava, \\ Ludvika Podeste 1875/17, 70833 Ostrava - Poruba, Czech Republic \\ ${ }^{2}$ Department of Building Structures, Faculty of Civil Engineering, VSB - Technical University of Ostrava, \\ Ludvika Podeste 1875/17, 70833 Ostrava - Poruba, Czech Republic
}

duc.tuan.le.st@vsb.cz, qui.nguyen.thanh.st@vsb.cz, radim.cajka@vsb.cz

DOI: $10.31490 /$ tces-2018-0018

\begin{abstract}
This article presents the numerical modeling of interaction between a reinforced concrete slab and subsoil using ABAQUS. Subsoil was simulated as both homogeneous half-space and inhomogeneous half-space. Reinforcement bars in the concrete slab were accurately modelled allowing capturing a precise deformation profile of the slab in interaction with subsoil. Input data for numerical analysis were adopted from a published work. Results of the study were verified on the basis of comparison with those of the previous study.
\end{abstract}

\section{Keywords}

Deformation, finite element method, interaction models, numerical models, reinforced concrete slab, subsoilstructure interaction.

\section{Introduction}

Researches on subsoil-structure interaction have been intensively done over recent years. Those studies have covered many aspects of the interaction [1], [2], [3], [4], [5], [6] and [7]. For instance, R. Cajka 2013 presented a method of determination of friction parameters for soilstructure interaction [5]. Stress strain analysis of elastic half-space using Gauss numerical integration and Jacobean of transformation was conducted by R. Cajka in 2013 [6] and results were further analyzed by R. Cajka and J. Labudkova in 2015 [7].

In addition, experimental measurements of stress and subsidence in subsoil were also carried out by many researchers such as G.X. Mei et al. 2005 [8], Cajka et al. 2014 [9] and [10]. M. Mohyla et al. 2017 [11] analyzed stress under foundation slab with a physical surface interface between foundation slab and the subsoil by experimental measurement. Measurements from site tests and experiments allow having a better understanding about behaviors of both subsoil and structure as well as their interaction.

Unfortunately, in-situ tests and site experiments are usually expensive and time consuming. As a result, numerical analysis of subsoil-structure interaction has become a current trend. Researchers and experts are improving and developing the analysis of subsoilstructure interaction based on finite element methods (FEM) or based on the combination of both experimental measurements and FEM. For example, R. Cajka 2014 [12] made a comparison of calculated values of settlement and stress state of concrete slab on subsoil and those values got from experiments. In 2014, R. Cajka and J. Labudkova [13] described how calculated deformations depend on parameters of soil environment modeled by 3D finite elements. Deformation and contact stress of the slab and subsidence of the subsoil were calculated by using two FEM programs, Scia Engineer [14] and Mkpinter (a non-commercial software created by Cajka R., co-author of this paper), in [15]. Numerical interaction model of reinforced concrete (RC) slab and subsoil was also modelled in ANSYS [16] with application of inhomogeneous half-space to get better subsoil behavior [17]. This model was also applied to simulate the interaction between subsoil and steel-fibre reinforced concrete slab in [18].

This research aimed at the analysis of the interaction between subsoil and RC slab under the scheme of FEM. The study can be considered as a continuing development of the work of [17] on which ABAQUS [19] is used instead of ANSYS and reinforcement bars in the concrete slab are modelled with more realistic 3D body. In addition, this work took into account of the influence of friction between the subsoil and the slab which was neglected in [17]. Furthermore, the non-linear material 
model of Mohr Coulomb was employed instead of Drucker-Prager model had been used in [17]. Using this model, it is assumed that the compressive strength far exceeds the tensile strength. To facilitate the comparison between results of this work and those of [17], input parameters (geological profile, dimensions of the subsoil and slab, boundary conditions of the subsoil and results from experimental loading test) of [17] were adopted here. Outcomes of parametric study were compared with those of [17].

\section{Numerical modeling in Abaqus}

It is necessary to underline that ANSYS was chosen to facilitate the work of [17]. Both ANSYS and ABAQUS have lots of things in common and they both can solve such a work of the research. However, ABAQUS was intentionally exploited here as an occasion of comparing analysis results from both programs to a specific subsoilstructure interaction problem.

Like ANSYS, ABAQUS is one of the powerful tools for non-linear finite element modeling and analysis of almost engineering problems. The main principle of ABAQUS is to use the Newton-Raphson algorithm to calculate and automatically adjust increments to give results. This program was selected as a simulation tool for the research due to its wide material modeling and metaphysics capabilities. The software also helps in solving the contact between subsoil and concrete slab in this work via $3 \mathrm{D}$ elements.

In this study, 3D finite elements in ABAQUS 2017 were used to create models for both subsoil and the slab as well as the interaction between them. As above mentioned, all input parameters of [17] were re-applied in these simulations.

First of all, 3D subsoil model was simulated as a halfspace in two cases: linear elastic homogeneous isotropic half-space and linear elastic inhomogeneous isotropic half-space. The former has constant value of modulus of deformability throughout its $6 \mathrm{~m}$ thick one-layer body while the latter includes 30 equal thickness soil layers of which values of deformability modulus varies by depth. The case of linear elastic inhomogeneous isotropic halfspace is to take into account of the heterogeneity of subsoil material. This choice allows a better description of subsoil behavior than the homogeneous one [17] and [18]. The 3D element, SOLID C3D8R, was selected to simulate the subsoil. It is an eight-node linear brick element with reduced integration (1 integration point). This only integration point is located in the middle of the element. One of the important parameters of subsoil is modulus of deformability. It can be determined by oedometer tests, laboratory tests or tests in situ as discussed in literatures [20] and [21]. In this research, calculation of modulus of deformability is inherited from formulas presented in [17] with minor revision as follows:

$$
E_{\text {def }, z}=E_{0}\left(1+z^{m}\right),
$$

where $E_{\text {def,z }}$ is the modulus of deformability (MPa) of the subsoil at $z$ depth, $E_{0}$ is the modulus of deformability (MPa) at the surface of subsoil, $z$ is the coordinate of considered layer of subsoil (m) in $z$ direction (depth), $\mathrm{m}$ is a coefficient depending on Poisson coefficient, $v$.

$$
m=\frac{1}{v}-2
$$

Input parameters of the subsoil model are summarized in table 1.

Tab. 1: Input parameters of the subsoil model.

\begin{tabular}{|l|c|c|}
\hline \multicolumn{1}{|c|}{ Parameters } & Unit & Value \\
\hline Dimensions of subsoil & $\mathrm{m}$ & $6 \times 6 \times 6$ \\
\hline $\begin{array}{l}\text { Mesh size used in the subsoil } \\
\text { model }\end{array}$ & $\mathrm{m}$ & $0.2 \times 0.2$ \\
\hline $\begin{array}{l}\text { Thickness of each layer in } \\
\text { inhomogeneous half-space, } z_{i}\end{array}$ & $\mathrm{~m}$ & 0.2 \\
\hline Poisson coefficient, $v$ & - & 0.35 \\
\hline $\begin{array}{l}\text { Modulus of deformability at the } \\
\text { surface of subsoil, } E_{0}\end{array}$ & $\mathrm{MPa}$ & 33.1 \\
\hline
\end{tabular}

Tab. 2: Input parameters of the slab.

\begin{tabular}{|l|c|c|}
\hline \multicolumn{1}{|c|}{ Parameters } & Unit & Value / Description \\
\hline Dimensions of slab & $\mathrm{m}$ & $2 \times 2 \times 0.12$ \\
\hline Cover thickness & $\mathrm{m}$ & 0.02 \\
\hline $\begin{array}{l}\text { Mesh size used in the } \\
\text { slab model }\end{array}$ & $\mathrm{m}$ & $0.2 \times 0.2$ \\
\hline $\begin{array}{l}\text { Poisson coefficient, } v \\
\text { - without crack } \\
\text { - with crack }\end{array}$ & - & 0.2 \\
\hline $\begin{array}{l}\text { Strength class of } \\
\text { concrete }\end{array}$ & class \\
\hline $\begin{array}{l}\text { Modulus of elasticity: } \\
\text { - without crack, } E_{c} \\
\text { - with crack, } E_{c}{ }^{I I}\end{array}$ & $\mathrm{GPa}$ \\
\hline $\begin{array}{l}\text { Reinforcement bars } \\
\mathrm{Cps}\end{array}$ & $\mathrm{p} 25 / 30$ \\
\hline $\begin{array}{l}\text { Elastic modulus of } \\
\text { reinforcement }\end{array}$ & $\mathrm{GPa}$ & $\begin{array}{c}27.5 \\
\text { and } 8.3\end{array}$ \\
\hline $\begin{array}{l}\text { Poisson coefficient of } \\
\text { reinforcement }\end{array}$ & - & 210 \\
\hline
\end{tabular}

Three variants of boundary conditions were adopted from [17], include:

- Variant A: vertical and horizontal shifts in the lower base of the subsoil model were hindered, node shifts of 4 peripheral walls of the subsoil model were not hindered,

- Variant B: vertical and horizontal shifts in the lower base of the subsoil model were hindered, horizontal node shifts of 4 peripheral walls of the subsoil model were hindered,

- Variant C: vertical and horizontal shifts in the 
lower base and in the 4 peripheral walls of the subsoil model were hindered.

Secondly, slab was also created by the 3D element SOLID C3D8R in 2 scenarios: without crack and with crack. Other parameters are depicted in table 2.

Furthermore, the subsoil-concrete slab model was loaded with a load force of $350 \mathrm{kN}$ within the loaded area of $200 \mathrm{~mm} \times 200 \mathrm{~mm}$. It is important to be noted that friction between the slab and the subsoil was taken into account as a coefficient of 0.3 in this work. Surface-tosurface contact scheme was used to mediate the interaction between the subsoil and the slab. The 3D numerical models of the slab and the subsoil are illustrated in figure 1.

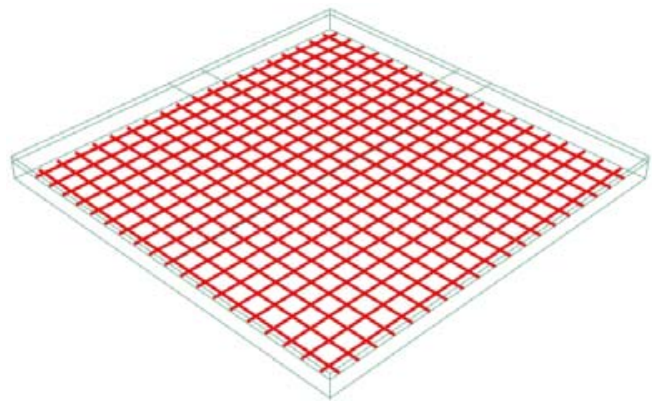

(a)

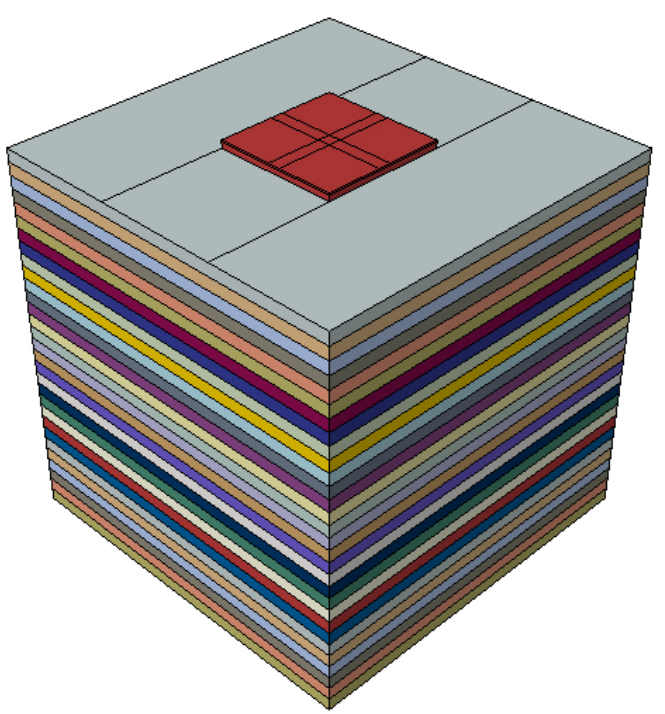

(b)

Fig. 1: 3D numerical models of the slab (a) and inhomogeneous subsoil (b).

\section{Parametric study}

Influence of inhomogeneity of the subsoil model was considered here through 9 different created 3D models (3 variants of boundary condition x 3 depths of the subsoil, $2 \mathrm{~m}, 4 \mathrm{~m}$ and $6 \mathrm{~m}$ ) of homogeneity half-space and another 9 different simulated 3D models of inhomogeneity halfspace. Figure 2 depicts the slab deformations with variable depths of the homogeneity half-space and inhomogeneity half-space at three boundary conditions.

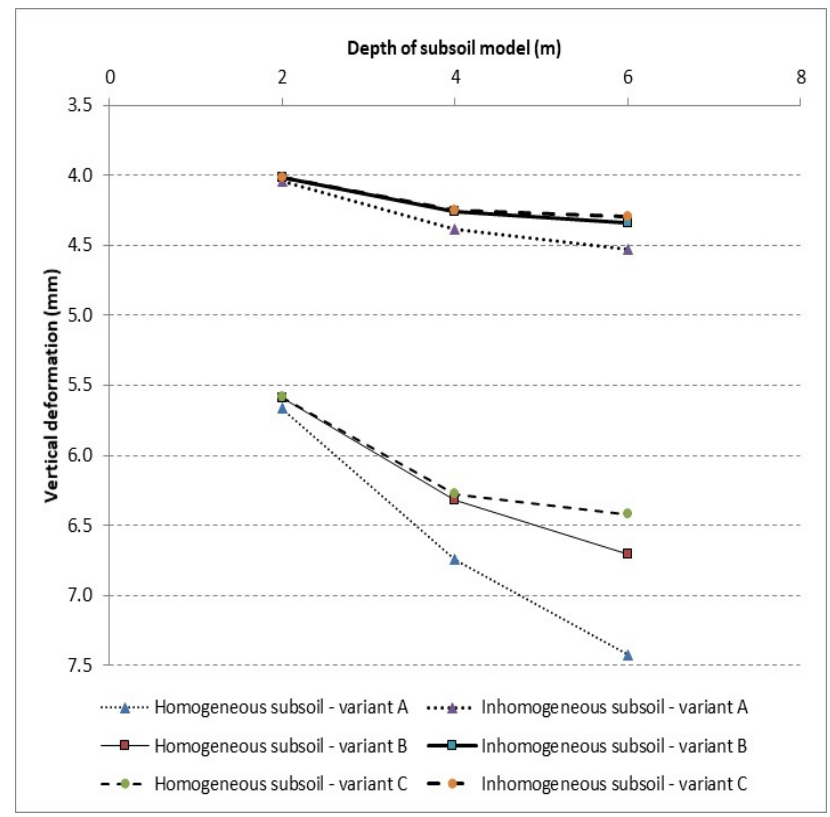

Fig. 2: Slab deformations in cases of homogeneity halfspace and inhomogeneity half-space.

It is noticeable from figure 2 that slab deformations increase with the increase of subsoil depth. In addition, boundary conditions had major influence to final vertical deformations of the slab. Furthermore, resulting vertical deformations in case of homogeneous half-space are larger than those of inhomogeneous half-space. A closer look at figure 2 reveals that the difference in values of vertical deformation (between the largest and the smallest value) in the middle of the RC slab in homogeneous subsoil model is almost 4 times larger than those in inhomogeneous one. This indicates that homogeneity or inhomogeneity of the subsoil significantly impact the slab vertical deflections. All these results confirmed conclusions of [17]. Vertical deformations in the middle of the RC slab with boundary condition B in this study (using ABAQUS) were compared with those of [17] (using ANSYS) as shown in figure 3. Variant B was selected because it is considered to be most likely to occur in practice among the three variants.

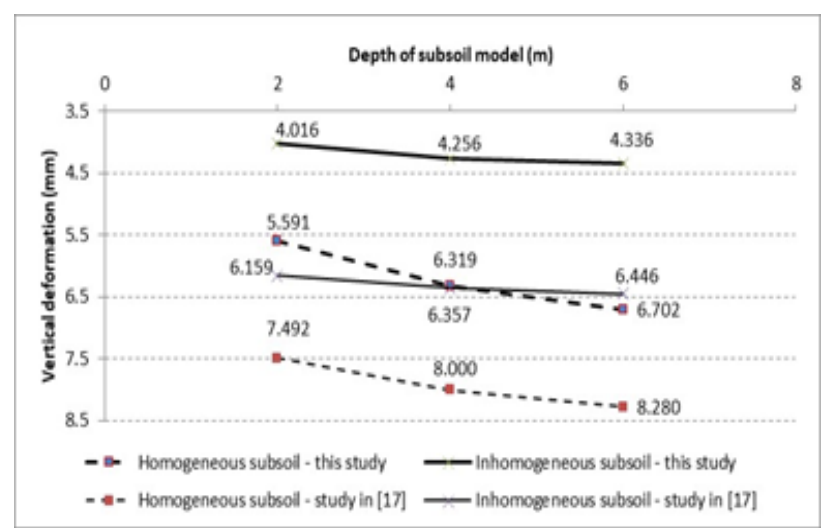

Fig. 3: Comparison of maximum slab deformations resulted from this work with those of [17]. 
It can be seen from figure 3 that the deformation line in case of homogeneous half-space in this research is almost parallel to that of [17]. The same situation also took place with case of inhomogeneous half-space. Resulted values of vertical deformation of this study are smaller than those of [17]. The difference in deformation values between this research and those of [17] are from $1.578 \mathrm{~mm}$ to $1.901 \mathrm{~mm}$ and from $2.101 \mathrm{~mm}$ to $2.143 \mathrm{~mm}$ in cases of homogeneity and inhomogeneity of the subsoil, respectively. Therefore, it can be inferred from the comparison that vertical deformation of the RC slab in considering interaction model analyzed by ANSYS is more conservative than that simulated by ABAQUS.

Influence of cracks in the slab to vertical deformations in the middle of the slab was also taken into account in this research. The main reason is that the cracks weaken rigidity of the slab and hence increase slab deformations. Only inhomogeneous half-space of the subsoil was considered here. Once again, results on slab deformations without and with cracks at boundary condition B are summarized in table 3 .

Tab. 3: Maximum vertical deformations of the slab with inhomogeneous subsoil model and variant B.

\begin{tabular}{|c|c|c|c|}
\hline \multirow{2}{*}{$\begin{array}{c}\text { Depth } \\
\text { (m) }\end{array}$} & \multicolumn{2}{|c|}{$\begin{array}{c}\text { Maximum vertical } \\
\text { deformations of the slab } \\
\text { (mm) }\end{array}$} & $\begin{array}{c}\text { Increase of } \\
\text { deformation } \\
\text { (\%) }\end{array}$ \\
\cline { 2 - 4 } & $\begin{array}{c}\text { Slab model } \\
\text { without } \\
\text { crack (a) }\end{array}$ & $\begin{array}{c}\text { Slab model } \\
\text { with cracks } \\
\text { (b) }\end{array}$ & {$[(\mathrm{b})-(\mathrm{a})] /(\mathrm{a})$} \\
\hline 2 & 4.016 & 5.061 & 26.02 \\
\hline 4 & 4.256 & 5.309 & 24.74 \\
\hline 6 & 4.336 & 5.388 & 24.26 \\
\hline
\end{tabular}

It is remarkable from table 3 that cracks increased vertical deformations in the middle of the slab at all three depths of subsoil model. This well agreed with the result of [17]. Amount of deformation increase was quite high, from $24.26 \%$ to $26.02 \%$. Figure 4 depicted the comparison between vertical deformations of the cracked and non-cracked slabs at boundary condition B in this study and those of [17].

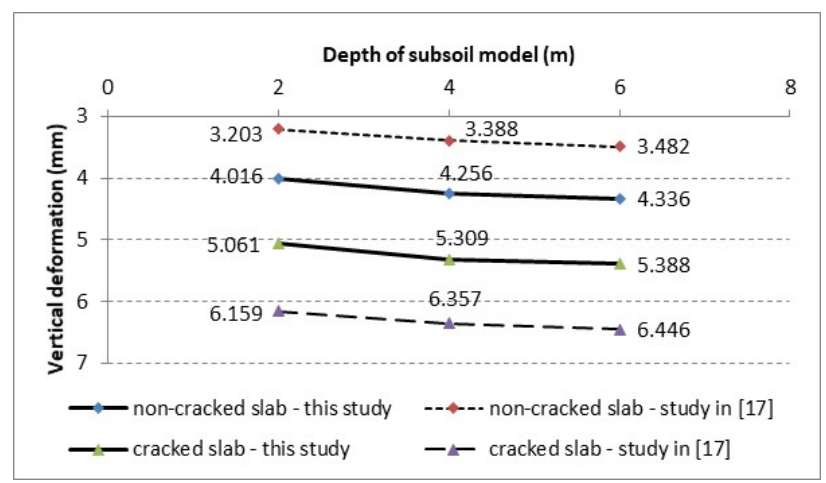

Fig. 4: Deformations of the cracked and non-cracked slabs of this work and those of [17].

It can be observed from figure 4 that deformation lines of the non-cracked and cracked slabs in this work and those of [17] have similar shape and they are likely to parallel to each other. Results from [17], however, demonstrated that cracks increased vertical deformations in the middle of the slab about $85 \%$ to $92 \%$ while the increasing amounts in this study were only $24 \%$ to $26 \%$. This resulted from the fact that a friction coefficient of 0.3 between the subsoil and the slab was taken into account in this research.

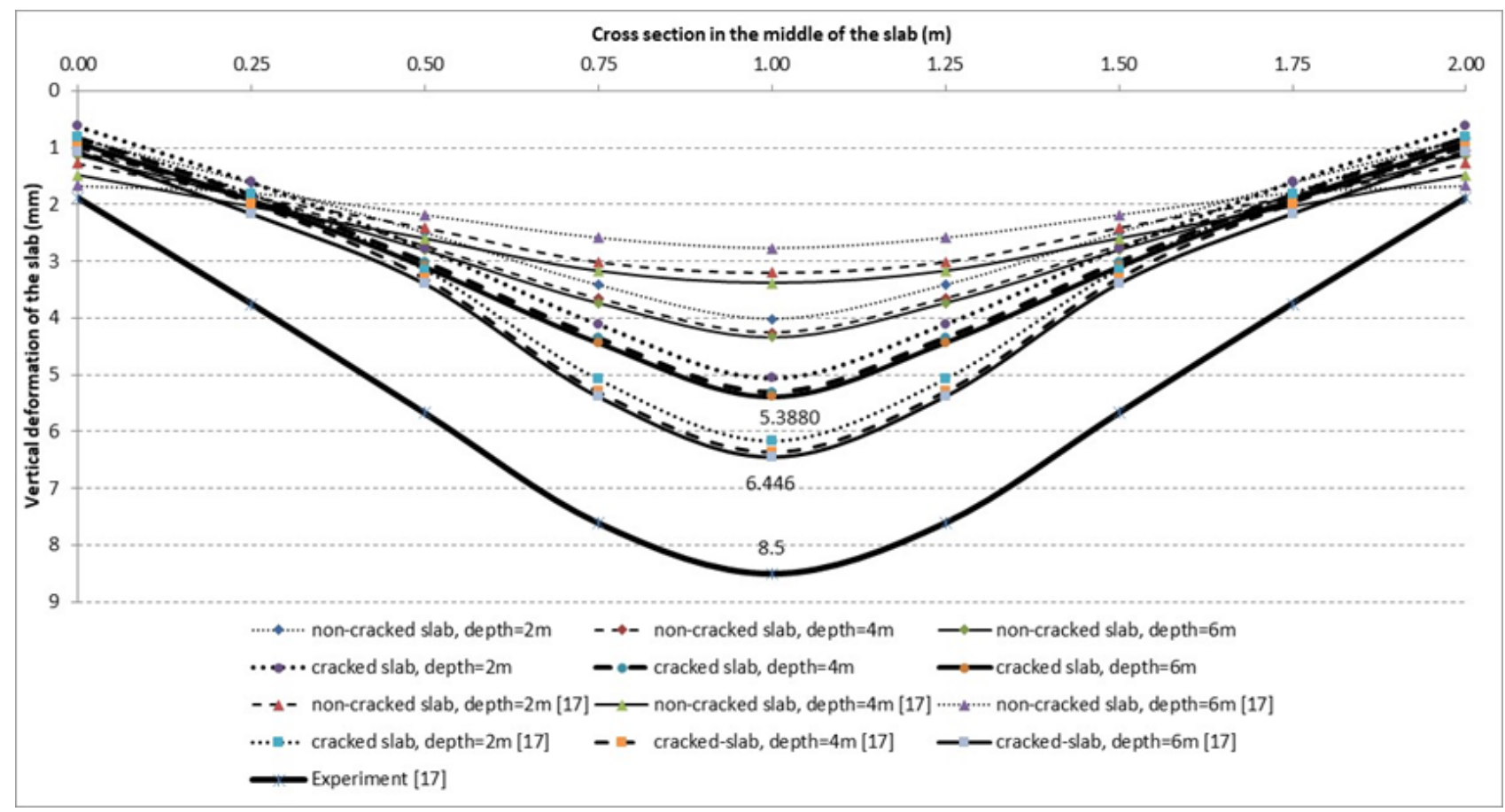

Fig. 5: Comparison of deformations of the cracked slab with the non-cracked slab. 
In addition, results on vertical deformations in a cross-section in the middle of the slab (without and with cracks) at boundary condition $\mathrm{B}$, obtained from ABAQUS are compared with accordingly results of [17]. The comparison is displayed in figure 5 included with the deformation curve of experiment adopted also from [17].

Please be kindly noted that all deformation curves in case of non-cracked slab were performed by light curves and the dark curves depicted deformation curves in case of cracked slab. It is quite clear from figure 5 that the closer the middle of the slab is, the larger difference of vertical deformation between non-cracked slab and cracked slab results. Maximum value of vertical deformation of cracked slab simulated by ABAQUS (this study) is $5.388 \mathrm{~mm}$ while that of cracked slab analyzed by ANSYS (study in [17]) is $6.446 \mathrm{~mm}$. This minor deviation $(1.058 \mathrm{~mm}$, about $16.4 \%)$ of vertical deformation can be explained firstly by the application of friction coefficient in the interactive model and secondly by the fact that reinforcement bars of the slab were accurately modeled in this study. It is also remarkable from figure 5 that the shape of deformation curves of cracked slab is quite similar to that of the deformation curve drew from site test by [17].

\section{Summary and Conclusions}

The interaction between a reinforced concrete slab and subsoil was analyzed using FEM by application of ABAQUS. Subsoil was modelled as both 3D homogeneous and inhomogeneous bodies to take into account of the influence of inhomogeneity of the subsoil to deformation of the slab. Two scenarios (without and with cracks) were integrated into the RC slab to consider impacts of cracks on deformation behavior of the slab. Reinforcement bars in the concrete slab were realistically simulated. Total of 36 interactive models were set up based on: variability of boundary conditions (3 variants), variation of depths of subsoil (3 different depths), homogeneity or inhomogeneity of the subsoil (2 options), cracked or non-cracked slab (2 scenarios). Friction between the slab and subsoil was also considered in the interaction. All input parameters were adopted from a literature (work in [17]).

Parameter study revealed that: (i) boundary conditions strong influenced to final vertical deformations of the slab; (ii) deformations of slab increased with the increase of subsoil depth; (iii) inhomogeneity of subsoil significantly impacted on slab resulted deformations; (iv) cracks weakened rigidity of the slab and increase slab deformations. These results confirmed conclusions of work in [17].

In addition, it can be inferred from the comparison between results from this research and those of [17] that vertical deformation of the slab would be reduced if friction between the slab and subsoil was taken into account in the analysis of interaction. Furthermore, lower vertical deformations of the slab (in comparison with those of [17]) would be observed if its reinforcement bars were realistically modelled.

It can also be concluded from this work that either ANSYS or ABAQUS can be efficiently employed in solving of subsoil-RC slab interaction problems.

\section{Acknowledgements}

The article preparation was supported by sources for conceptual development of research, development and innovations at VŠB-Technical University of Ostrava for year 2018, which were granted by the Ministry of Education, Youth and Sports of the Czech Republic.

\section{References}

[1] KUKLIK, P. Preconsolidation, structural strength of soil, and its effect on subsoil upper structure interaction. Engineering Structures. 2011, vol. 33, pp. 1195-1204. DOI: 10.1016/j.engstruct.2010.12.041.

[2] CAJKA, R. KRIVY, V. and SEKANINA, D. Design and Development of a Testing Device for Experimental Measurements of Foundation Slabs on the Subsoil. Transactions of the VSB - Technical University of Ostrava, Construction Series. 2011, vol. 11, iss. 1, pp. 1-5. ISSN (Online) 1804-4824. ISSN (Print) 1213-1962.

[3] ULITSKY, V.M., SHASHKIN, A.G., SHASHKIN, K.G., VASENIN, V.A., LISYUK, M.B. and DASHKO, R.E. Interaction between structures and compressible subsoils considered in light of soil mechanics and structural mechanics. In: 18th International Conference on Soil Mechanics and Geotechnical Engineering. Paris, 2013.

[4] ABOUTALEBI, M., ALANI, A., RIZZUTO, J. and BECKETT, D. Structural behaviour and deformation patterns in loaded plain concrete ground-supported slabs. Structural Concrete. 2014, Vol. 15, iss. 1, pp. 81-93.

[5] CAJKA, R. Horizontal Friction Parameters in Soil Structure Interaction Tasks. Advanced Materials Research. 2013, vol. 818 (2013), pp 197-205. Trans Tech Publications, Switzerland. DOI:10.4028/www.scientific.net/AMR.818.197.

[6] CAJKA, R. Analysis of Stress in Half-space using Jacobian of Transformation and Gauss Numerical Integration. Advanced Materials Research. 2013, vol. 818 (2013), pp 178-186. Trans Tech Publications, Switzerland. DOI:10.4028/www.scientific.net/AMR.818.178.

[7] CAJKA, R. and LABUDKOVA, J. Fibre concrete 
foundation slab experiment and FEM analysis. Key Engineering Materials. 2015, vol. 627(2015), pp 441-444. Trans Tech Publications, Switzerland.

[8] MEI, G.X., YIN, J.H., ZAI, J.M. and ZHU, G.F. Immediate settlement of a rectangular foundations embedded in a saturated isotropic elastic soil. Geotechnical Engineering. 2005, vol. 36(2), pp. 109-113. ISSN 0046-5828.

[9] CAJKA, R., BURKOVIC, K. and FOJTIK, R. Experimental Soil - Concrete Plate Interaction Test and Numerical Models. Key Engineering Materials. 2014, Vols. 577-578 (2014), pp. 33-36. Trans Tech Publications, Switzerland. DOI:10.4028/www.scientific.net/KEM.577-578.33.

[10] CAJKA, R., BURKOVIC, K. and BUCHTA, V. Foundation Slab in Interaction with Subsoil. Advanced Materials Research. 2014, vols. 838-841 (2014), pp. 375-380. Trans Tech Publications, Switzerland.DOI:10.4028/www.scientific.net/AMR. 838-841.375.

[11] MOHYLA, M., VOJTASIK, K., STOLARIK, M., PINKA $M$. and LAHUTA, H. Experimentally measurement and analysis of stress under foundation slab. International Journal of GEOMATE. 2017, vol. 13, iss. 35, pp. 128-135. ISSN 2186-2990. DOI:10.21660/2017.35.6694.

[12] CAJKA, R. Comparison of the calculated and experimentally measured values of settlement and stress state of concrete slab on subsoil. Applied Mechanics and Materials. 2014, vols. 501504 (2014), pp. 867 -

876. Trans Tech Publications, Switzerland. DOI: 10. 4028/www.scientific.net/AMM.501-504.867.

[13] CAJKA, R. and LABUDKOVA, J. Dependence of deformation of a plate on the subsoil in relation to the parameters of the 3D model. International Journal of Mechanics. 2014, vol. 8, pp. 208-215. ISSN 1998-4448.

[14] Scia Engineer. Available at: https://www.scia.net/en/software/scia-engineer.

[15] CAJKA, R. and LABUDKOVA, J. Comparison of results of analyses the foundation slab calculated by two FEM programs. Advanced Materials Research. 2015, vols. 1065-1069 (2015), pp. 1052-1056, Trans Tech Publications, Switzerland. DOI:10.4028/www.scientific.net/AMR.16051069.1052.

[16] Ansys. Available at: https://www.ansys.com.

[17] LABUDKOVA, J. and CAJKA, R. Numerical modeling of the subsoil-structure interaction. Key Engineering Materials. 2016, vol. 691, pp. 333-343. Trans Tech Publications, Switzerland.

[18] LABUDKOVA, J. and CAJKA, R. 3D numerical model in nonlinear analysis of the interaction between subsoil and SFCR slab. International
Journal of GEOMATE. 2017, vol. 13, iss. 35, pp. 120-127, Geotec., Const. Mat. \& Env. ISSN 21862990 .

DOI:

http://dx.doi.org/10.21660/2017.35.6689.

[19] Abaqus. Available at: https://www.simuleon.com/simulia-abaqus.

[20] DULACSKA, E. Soil settlement effects on buildings. Elsevier, 1992. ISBN 0444986898 9780444986894.

[21] DIN Standard 18134. Determining the deformation and strength characteristics of soil by the plate loading test. 2001.

\section{About Authors}

Tuan Duc LE was born in Danang, Vietnam. He received his M.Sc. from ROSE school (IUSS, University of Pavia, Italy) in 2007 and his M.E. from HCMUT (Vietnam) in 2005. His research interests include: reinforced concrete structures, steel structures, FE modeling, structural dynamics, blast loading, seismic design, probabilistic simulation, reliability of structures, chloride diffusion.

Qui Thanh NGUYEN was born in Vinh, Vietnam. He received his M.E. from HCMC UNIVERSITY OF TRANSPORT (Vietnam) in 2005. His research interests include: FE analysis, structural analysis, FE modeling and structural dynamics.

Radim CAJKA is well established expert and professor in the field of civil engineering. He is currently Dean of Faculty of Civil Engineering, VŠB - Technical University Ostrava, Czech Republic. His research interests include: concrete structures, foundations of structures on undermined areas, soil - structure interaction, FEM, temperature loaded structures, fire resistance of structures, structural dynamics, civil engineering materials, seismic design, earthquake engineering, concrete durability, geotechnical engineering, tunneling, soil mechanics, civil engineering solfware. 